\title{
Determination of Ochratoxin A in Selected Cereal Grains Retailed in Nairobi County, Kenya
}

\author{
Peter K. Karoki ${ }^{1}$, Wilson M. Njue ${ }^{1}$, Sauda Swaleh ${ }^{1}$, Ezekiel K. Njoroge ${ }^{2}$ \& Cecilia W. Kathurima ${ }^{2}$ \\ ${ }^{1}$ Chemistry department, Kenyatta University, Kenya \\ ${ }^{2}$ Coffee Research Foundation, Ruiru, Kenya \\ Correspondence: Wilson Njue, Department of Chemistry, Kenyatta University, P.O. Box 43844-00100, Nairobi, \\ Kenya. Tel: 254-722-234-277. E-mail: njue.wilson@ku.ac.ke
}

Received: May 14, 2018 Accepted: June 8, 2018 Online Published: August 2, 2018

doi:10.5539/jfr.v7n5p79 URL: https://doi.org/10.5539/10.5539/jfr.v7n5p79

\begin{abstract}
Ochratoxin A (OTA) belongs to a group of mycotoxins which are a key threat to quality of cereals based foodstuff. Mycotoxins are toxic, carcinogenic, nephrotoxic, neurotoxic and immunotoxic secondary metabolites of certain molds occurring in crop produce and their products. OTA occurs naturally in majority of foodstuffs such as coffee, cereal grains and beverages. The aim of the study was to determine the levels of OTA in cereal grains sampled from various market outlets in Nairobi County, Kenya. The levels of OTA were determined from 27 samples of finger millet (Eleusine coracana), wheat (Triticum aestivum) and sorghum (Sorghum bicolor) grains. The levels of OTA in grains was determined by High Performance Liquid Chromatography (HPLC). The results indicated that wheat grains recorded the highest contamination $(2.1478 \pm 0.3061 \mathrm{ng} / \mathrm{g})$ followed by sorghum $(1.0311 \pm 0.0635 \mathrm{ng} / \mathrm{g})$, while finger millet recorded the lowest levels $(0.6918 \pm 0.0315 \mathrm{ng} / \mathrm{g})$. Cereal samples from Gikomba outlet had a higher contamination $\left(1.1750 \pm 0.0353-3.8147 \pm 0.4317 \mu \mathrm{g} \mathrm{kg}^{-1}\right)$ than those from Githurai outlet $\left(0.1244 \pm 0.0795-0.4808 \pm 0.0321 \mu \mathrm{g} \mathrm{kg}^{-1}\right)$. OTA levels in samples from Nyamakima outlet were below the detection limit of HPLC $(0.03 \mu \mathrm{g} / \mathrm{L})$. Though levels are lower than maximum allowable limits for OTA in cereals in the European Union $(5 \mu \mathrm{g} / \mathrm{kg})$ and United Kingdom $(10 \mu \mathrm{g} / \mathrm{kg})$, chronic exposure can have serious health risk. The study provides baseline data on the levels of OTA in finger millet, sorghum and wheat grains retailed in Nairobi County, Kenya. The information creates awareness on the potential health risk associated with chronic exposure to OTA from cereals.
\end{abstract}

Keywords: cereals, HPLC, Kenya, mycotoxins, Ochratoxin A.

\section{Introduction}

Mycotoxins are toxic secondary metabolites produced mainly by Aspergillus and Penicillium mold species. They are disease and death causing metabolites to humans and animals (Bennett \& Klich, 2003). Mycotoxins producing species colonize agricultural products during crop growth, harvesting, storage or even in processing (Fernandez-cruz, Mansilla \& Tadeo, 2010). Their occurrence is influenced interdependently by physical, biological and chemical factors (Milani, 2013; Milicevic, Nesic \& Jaksic, 2015).

Aflatoxins, ochratoxins, zearelenone, deoxynivarenol, fumonisins, trichothecenes and tremogenics toxins are major mycotoxins of great health and economic importance (Pitt, 2000; Atanda et al., 2011). Their presence in food in notably high levels is capable of causing chronic and acute toxic effects in both animals and humans (Milicevic et al., 2015).

Cereals and cereal products are widely produced and consumed in large quantities worldwide. With increased production of wheat, sorghum and millets in Kenya, and world at large, there is possibility of widespread mycotoxins contamination. Stored cereals and barley are prone to ochratoxins contamination (Misihairabgwi, Ezekiel, Sulyok, Shephard \& Krska, 2017). Ochratoxins occur naturally in various forms, mainly Ochratoxin A (OTA) (1), ochratoxin B (2) and ochratoxin C (3) as shown in Figure 1 (Reddy \& Bhoola, 2010). Of these, OTA is the most prevalent and toxic (Sorrenti et al., 2013). OTA is produced by Aspergillus ochraceus, Aspergillus carbonarius and Penicillium verrucossum molds in tropical and temperate climate regions (Héctor, Marta, Jorge \& Hilary, 2003; Reddy \& Bhoola, 2010). It mainly occurs in wheat, corns, coffee, millets, sorghum, barley, grapes, beverages and other cereal products (Dall'Asta, Galaverna, Dossena \& Marchelli, 2004; Zinedine, 2010). 
<smiles>C[C@H]1Cc2c(Cl)cc(C(=O)N[C@@H](Cc3ccccc3)C(=O)O)c(O)c2C(=O)O1</smiles>

(1) OTA<smiles>C[C@@H]1Cc2ccc(C(=O)N[C@@H](Cc3ccccc3)C(=O)O)c(O)c2C(=O)O1</smiles>

(2) ОТВ<smiles>CCOC(=O)[C@H](Cc1ccccc1)NC(=O)c1cc(Cl)c2c(c1O)C(=O)O[C@H](C)C2</smiles>

Figure 1. structures of ochratoxins

According to Nugroho, (2014), OTA has been one of the disturbing contaminant in Indonesian coffee (Nugroho, 2014). Consumption of mycotoxins contaminated food substances has been linked to diseases like cancer, nephropathy and increased kidney diseases in human (Zinedine, 2010) and animals (Pitt, 2000; Reddy \& Bhoola, 2010; Hope \& Hope, 2011).

Establishment of OTA levels in cereals and other foodstuffs in some countries has enabled them to formulate regulations on maximum allowable OTA levels in their cereals and other commodities. European Union has set a limit of $5 \mu \mathrm{g} / \mathrm{kg}$ and $3 \mu \mathrm{g} / \mathrm{kg}$ in cereals and cereal products respectively (Hans \& Marco, 2005; Barber, 2007). In 2001, Denmark, Romania and France had their acceptable and recommended values set at $5 \mu \mathrm{g} / \mathrm{kg}$, while United Kingdom has set it at $10 \mu \mathrm{g} / \mathrm{kg}$ with Switzerland and Netherlands setting limits at $2 \mu \mathrm{g} / \mathrm{kg}$ and $3 \mu \mathrm{g} / \mathrm{kg}$ respectively (Sasmal \& Mazumder, 2001). However, Kenya has no set limits of OTA in cereals and related products. This is partly due to limited or no information on its occurrence. Therefore this study aimed at determining and documenting the levels of OTA in finger millet, wheat and sorghum grains retailed in Nairobi County, Kenya.

\section{Materials Studied}

Twenty seven (27) samples of Sorghum grains, finger millet grains and wheat grains were obtained from the main cereal markets (Gikomba, Nyamakima and Githurai) within Nairobi County, Kenya. They were transported in sterile sample collection bags to the analytical laboratory in Coffee Research Foundation (CRF), Ruiru, Kenya. The samples were ground and stored at $-4{ }^{\circ} \mathrm{C}$ prior to analysis.

\section{Study Area}

Study was conducted within Nairobi County, Kenya, occupying about $669 \mathrm{~km}^{2}$. The county is located $1684 \mathrm{~m}$ above the sea level at $1.28^{\circ} \mathrm{S}$ and $36.82^{\circ} \mathrm{E}$. It has a population of more than 4 million people and acts as major market for cereal grains grown from various parts of Kenya (Kenya National Bureau of Statistics [KNBS], 2017).

\section{Methods and Techniques}

\subsection{Chemicals and Reagents}

Ochratoxin A standard stock solution $(10 \mu \mathrm{g} / \mathrm{L})$ in acetonitrile was purchased from Sigma Aldrich (UK). HPLC grade acetonitrile, water and acetic acid were obtained from Sigma Aldrich. Analytical grade chloroform, toluene, ethyl acetate- $90 \%$, formic acid-85\%, anhydrous sodium sulphate, methyl alcohol, acetone, diethyl ether and $\mathrm{HCl}$ were procured from Kobian Scientific (Kenya) Ltd. HyperSep ${ }^{\mathrm{TM}}$ C18 Cartridges were purchased from Thermo Fisher Scientific.

\subsection{Preparation of Ochratoxin A Standard Solutions}

Ochratoxin A standard solutions used in generating a calibration curve were of concentrations $2 \mu \mathrm{g} / \mathrm{L}, 4 \mu \mathrm{g} / \mathrm{L}, 6$ $\mu \mathrm{g} / \mathrm{L}, 8 \mu \mathrm{g} / \mathrm{L}$ and $10 \mu \mathrm{g} / \mathrm{L}$. They were prepared by serial dilution of $10 \mu \mathrm{g} / \mathrm{L}$ OTA standard stock solution.

\subsection{Ochratoxin A Extraction}

Extraction was done according to guidelines by Braicu, Puia, Bodoki, and Socaciu (2008). To $10 \mathrm{~g}$ of sample in 
$250 \mathrm{~mL}$ conical flask, $50 \mathrm{~mL}$ of chloroform was added and sonicated for 10 minutes at room temperature. The extract was filtered under vacuum and washed once with $50 \mathrm{~mL}$ of distilled water. Chloroform extract was dried over $20 \mathrm{~g}$ of anhydrous sodium sulphate and concentrated to dryness on a rotary evaporator at $50{ }^{\circ} \mathrm{C}$. The residue was redissolved in $4 \mathrm{~mL}$ acetonitrile. The extract was stored at $-4{ }^{\circ} \mathrm{C}$ awaiting the analysis.

\subsection{Clean-up}

The sample extract was cleaned according to method described by Ali et al., (2010). The Solid Phase Extraction (SPE) columns were pre-conditioned with $4 \mathrm{~mL}$ of deionized water before loading the sample at a flow rate of 1 $\mathrm{mL} / \mathrm{min}$ and then washed thrice with $1 \mathrm{~mL} \mathrm{HCl}(\mathrm{pH}=1)$ followed by $\mathrm{HCl}$ and acetonitrile mixture $(6: 4)$, and eventually $10 \mathrm{~mL}$ of deionized water. Columns were then dried with $4 \mathrm{~mL}$ of $0.01 \%$ acetic acid in acetonitrile at a flow rate of $5 \mathrm{~mL} / \mathrm{min}$ before eluting OTA with $2 \mathrm{~mL}$ of $2 \%$ acetic acid in methanol at a flow rate of 0.8 $\mathrm{mL} / \mathrm{min}$. The resulting eluents were evaporated to dryness and re-dissolved in $4 \mathrm{~mL}$ of pure acetonitrile before the analysis.

\subsection{High Performance Liquid Chromatography (HPLC)}

The specifications for HPLC (Perkin-Elmer) used were: fluorescence detection, excitation and emission wavelengths $332 \mathrm{~nm}$ and $472 \mathrm{~nm}$, a binary LC pump model 250, a loop injection of $20 \mu \mathrm{L}$, analytical C18 column $(25 \mathrm{~cm} \times 4.6 \mathrm{~mm}, 5 \mu \mathrm{m})$, isocratic elution solvent system of acetonitrile : water : acetic acid (51:47:2) with flow rate of $1 \mathrm{~mL} / \mathrm{min}$ and a computerized data collecting system. The run time was 4 minutes at ambient temperature. Limit of detection was $0.03 \mu \mathrm{g} / \mathrm{L}$. OTA was eluted after 2.533 minutes (Figure 2).

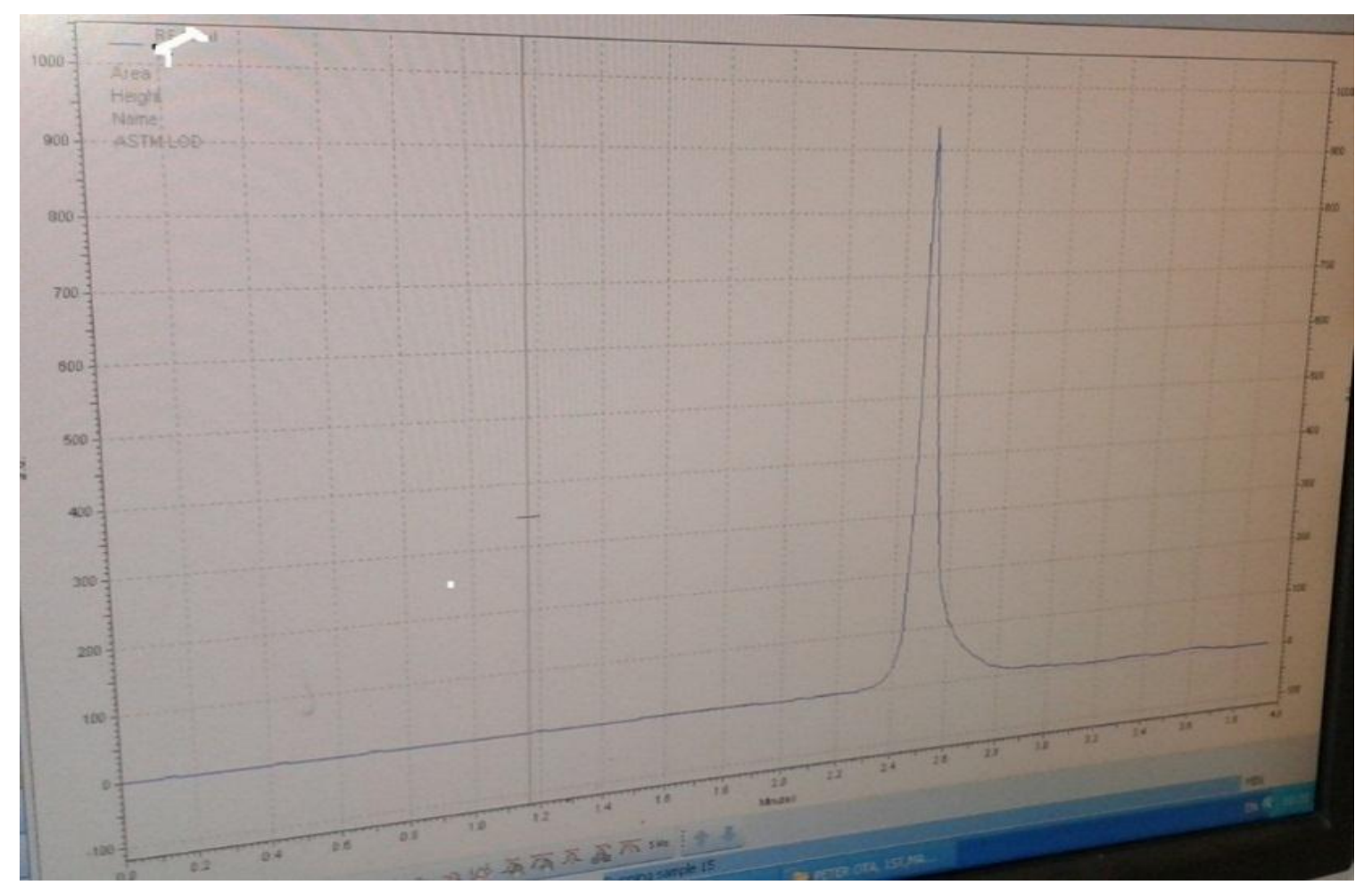

Figure 2. HPLC Chromatogram of OTA standard

The peak areas of the chromatograms were plotted against the OTA concentrations to produce the calibration curve shown in figure 3 . Samples were then analysed in triplicates. 


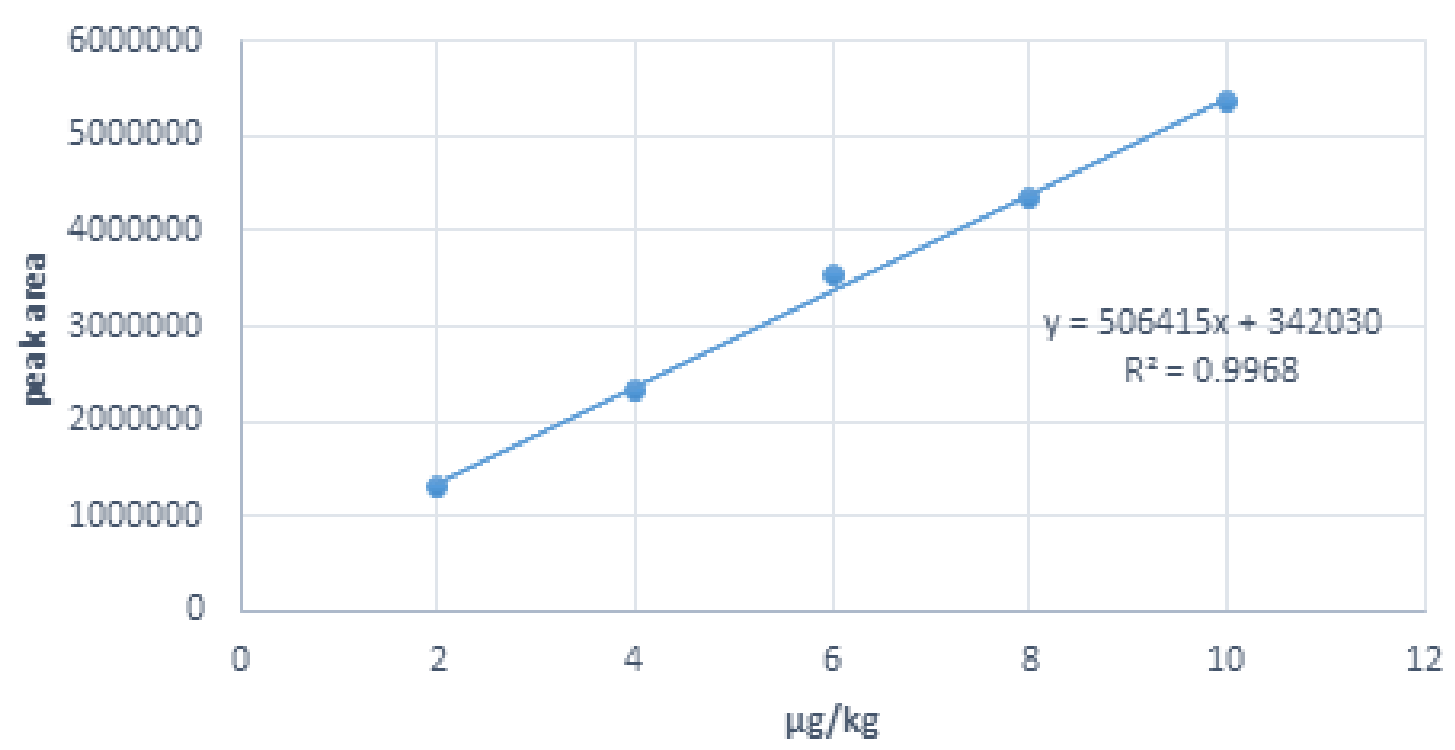

Figure 3. Calibration curve

\section{Results}

Data obtained from HPLC showed ochratoxin A occurred in wheat, finger millet and sorghum grains at varying concentrations as shown in Table 1.

Table 1. OTA concentration in wheat, finger millet and sorghum grains in $\mathrm{ng} / \mathrm{g}$

\begin{tabular}{lllll}
\hline & Gikomba & Githurai & Nyamakima & Overall Mean $^{\mathbf{c}}$ \\
\hline Finger millet & $1.1750 \pm 0.0353^{\mathbf{e}}$ & $0.2086 \pm 0.0271^{\mathbf{a}}$ & ND & $\mathbf{0 . 6 9 1 8} \pm \mathbf{0 . 0 3 1 5}^{\mathbf{c}}$ \\
\hline Sorghum & $1.9378 \pm 0.0417^{\mathbf{f}}$ & $0.1244 \pm 0.0795^{\mathbf{a}}$ & ND & $\mathbf{1 . 0 3 1 1} \pm \mathbf{0 . 0 6 3 5}^{\mathbf{d}}$ \\
\hline Wheat & $3.8147 \pm 0.4317^{\mathbf{g}}$ & $0.4808 \pm 0.0321^{\mathbf{b}}$ & ND & $\mathbf{2 . 1 4 7 8} \pm \mathbf{0 . 3 0 6 1} 1^{\mathbf{f}}$ \\
\hline
\end{tabular}

Note: Means followed by a different letter are significantly different. Those followed by same letter are not significantly different at $95 \%$ confidence level.

\section{Discussion}

Results in Table 1 shows that OTA levels in cereal grains ranged from $1.1750 \pm 0.0353 \mathrm{ng} / \mathrm{g}$ to $3.8147 \pm 0.4317$ $\mathrm{ng} / \mathrm{g}$ in samples obtained from Gikomba outlet, and from $0.1244 \pm 0.0795 \mathrm{ng} / \mathrm{g}$ to $0.4808 \pm 0.0321 \mathrm{ng} / \mathrm{g}$ in samples from Githurai outlet. Statistical analysis showed significant variation in OTA contamination of cereals in Gikomba outlet, with wheat grains recording the highest value $(3.8147 \pm 0.4317 \mathrm{ng} / \mathrm{g})$ followed by sorghum grains which OTA levels of $1.9378 \pm 0.0417 \mathrm{ng} / \mathrm{g}$. Finger millet recorded the lowest OTA levels $(1.1750 \pm 0.0353$ $\mathrm{ng} / \mathrm{g}$ ) among the cereal samples sourced from Gikomba outlet. Whereas there was no significant difference in OTA values between finger millet $(0.2086 \pm 0.0271 \mathrm{ng} / \mathrm{g})$ and sorghum grains $(0.1244 \pm 0.0795 \mathrm{ng} / \mathrm{g})$ from Githurai outlet, wheat grains had significantly higher OTA values of $0.4808 \pm 0.0321 \mathrm{ng} / \mathrm{g}$. Though prolonged exposure can have serious health risks, these levels are, however, lower than the maximum allowable limit observed by countries which have regulations on OTA level in cereals like in European Union (Hans \& Marco, 2005; Barber, 2007). Indonesia and Singapore have their limit at a maximum of $5 \mathrm{ng} / \mathrm{g}$ and $2.5 \mathrm{ng} / \mathrm{g}$ respectively (Anukul, Vangnai \& Mahakarnchanakul, 2013). OTA levels were not detectable in samples of cereal grains from Nyamakima market.

OTA contamination of samples of wheat grains from Gikomba outlet $(3.8147 \pm 0.4317 \mathrm{ng} / \mathrm{g})$ was significantly higher than that of wheat grains from Githurai outlet $(0.4808 \pm 0.0321 \mathrm{ng} / \mathrm{g})$ at $95 \%$ confidence level. Though cereals might have originated from different sources, selling and storage structures in Gikomba were poorer than in Githurai, hence making these grain to be more susceptible to attack by ochratoxigenic mold due to exposure to mold growth conditions. However, the observed levels of OTA in wheat grains retailing in Nairobi County were lower than those in stored wheat from Great Lake Regions of Canada which was reported as $14.7 \pm 7.9 \mathrm{ng} / \mathrm{g}$ (Limay-Rios, Miller \& Schaafsma, 2017). 
On average, finger millet had the least contamination among the three cereals studied. Statistical analysis showed that OTA contamination in finger millet was significantly higher in samples from Gikomba outlet $(1.1750 \pm 0.0353 \mathrm{ng} / \mathrm{g})$ than in those from Githurai outlet $(0.2018 \pm 0.0271 \mathrm{ng} / \mathrm{g})$. This significant difference was attributed to difference in storage conditions. The mean OTA levels in finger millet retailed in Nairobi was however, not as high as that reported for Nigerian finger millet, $0-14.4 \mathrm{ng} / \mathrm{g}$, (Hertveldt et al., 2016). OTA was not detected in samples from Nyamakima market. The storage facilitates in Nyamakima are well designed such that cereals are not exposed to moisture, reducing the chances of OTA contamination.

Although OTA was not detectable in sorghum samples from Nyamakima outlet, OTA contamination in sorghum samples from Gikomba outlet $(1.9378 \pm 0.0417 \mathrm{ng} / \mathrm{g})$ was significantly higher than in sorghum samples from Githurai outlet $(0.1244 \pm 0.0795 \mathrm{ng} / \mathrm{g})$. However, the overall mean levels of OTA in sorghum retailed in Nairobi County $(1.0311 \pm 0.0635 \mathrm{ng} / \mathrm{g})$ was not as high as to those reported in Tunisia where the OTA content in sorghum was $1.93 \mathrm{ng} / \mathrm{g}$ (Oueslati, Blesa, Molto, Ghorbel \& Manes, 2014).

The overall OTA mean content in wheat was $2.1478 \pm 0.3061 \mathrm{ng} / \mathrm{g}$ and $0.6918 \pm 0.0315 \mathrm{ng} / \mathrm{g}$ for finger millet, while sorghum grains had a level of $1.0311 \pm 0.0635 \mathrm{ng} / \mathrm{g}$. statistical analysis showed significant variation between these values. Significantly higher OTA levels in wheat than in other cereal grains shows that wheat is more susceptible to mold infestation than other cereals.

The variation in OTA contamination in samples between market outlets was attributed to difference in storage conditions that promote the growth of molds (Duarte, Pena \& Lino, 2010; Volkova, 2013). The selling and storage structures in Githurai are relatively well designed such that cereals are relatively less exposed unlike in Gikomba market. Due to congestion and leaking structures in Gikomba, cereals are more exposed to moisture, hence making them more favourable for the growth of ochratoxigenic fungi leading to higher production of OTA. Storage and selling structures in Nyamakima are properly roofed and maintained than in other markets, reducing the likelihood of molds growth. Another factor that could have contributed to this variation is the source from which grains are obtained. During the course of this study, it was found that different sellers prefer buying cereals from different sources. This implies that cereals from different sources could have different levels of contamination.

\section{Conclusion}

The samples of the three cereals retailed in Nairobi County were contaminated with OTA. The levels varied among the samples and from market to market. Wheat, the second most important cereal crop to maize in Kenya, had the highest levels of OTA $(2.1478 \pm 0.3061 \mathrm{ng} / \mathrm{g})$ followed by sorghum $(1.0311 \pm 0.0635 \mathrm{ng} / \mathrm{g})$. Finger millet recorded the least contamination with a level of $0.6918 \pm 0.0315 \mathrm{ng} / \mathrm{g}$. These levels are lower than those observed in other countries.

The observed variability of OTA levels in grains from various outlet markets begs for increased awareness and regular surveillance for OTA contamination. Given the wide usage of cereals in Kenya, it was important to assess the level OTA contamination in finger millet, sorghum and wheat grains retailed in Nairobi County, Kenya. Post-harvest strategies in proper storage of grains should be encouraged in order to minimize mycotoxin producing molds growth.

\section{Acknowledgement}

The authors would like to acknowledge the Government of Kenya through African Development Bank (ADB) for the study support, Department of Chemistry, Kenyatta University and Coffee Research Foundation (Ruiru, Kenya) for their technical support.

\section{References}

Ali, W. H., Derrien, D., Alix, F., Pérollier, C., Lépine, O., Bayoudh, S., Chapuis-Hugon, F., \& Pichon, V. (2010). Method for Selective Solid Phase Extraction of Ochratoxin Using Molecularly Imprinted Polymers (Mip) and Automated Protocol. Retrieved from

http://affinisep.com/media/application_note_ochratoxin_A_automate_gilson_056182200_1514_01092011. pdf

Anukul, N., Vangnai, K., \& Mahakarnchanakul, W. (2013). Significance of Regulation Limits in Mycotoxin Contamination in Asia and Risk Management Programs at the National Level. Journal of Food and Drug Analysis, 21(3), 227-241. https://doi.org/10.1016/j.jfda.2013.07.009

Atanda, S. A., Pessu, P. O., Agoda, S., Isong, I. U., Adekalu, O. A., Echendu, M. A., \& Falade, T. C. (2011). Fungi and Mycotoxins in Stored Foods. African Journal of Microbiology Research, 5(25), 4373-4382. 
https://doi.org/10.5897/AJMR11.487

Barber, M. (2007). The Uk Code of Good Storage Practice to Reduce Ochratoxin a in Cereals. Food Standards Agency. Retrieved from

https://www.food.gov.uk/sites/default/files/multimedia/pdfs/ochratoxinacop.pdf

Bennett, J. W., \& Klich, M. (2003). Mycotoxins. Clinical microbiology reviews, 16, 497-516. https://doi.org/10.1128/CMR.16.3.497-516.2003

Braicu, C., Puia, C., Bodoki, E., \& Socaciu, C. (2008). Screening and Quantification of Aflatoxins and Ochratoxin A in Different Cereals Cultivated in Romania Using Thin-Layer Chromatography-Densitometry. Journal of Food Quality, 31, 108-120. https://doi.org/10.1111/j.1745-4557.2007.00187.x

Dall'Asta, C., Galaverna, G., Dossena, A., \& Marchelli, R. (2004). Reversed-Phase Liquid Chromatographic Method for the Determination of Ochratoxin A in Wine. Journal of Chromatography A, 1024, 275-279. https://doi.org/10.1016/j.chroma.2003.10.025

Duarte, S. C., Pena, A., \& Lino, C. M. (2010). A Review on Ochratoxin A Occurrence and Effects of Processing of Cereal and Cereal Derived Food Products. Food Microbiology, 27, 187-198. https://doi.org/10.1016/j.fm.2009.11.016

Fernandez-cruz, M. L., Mansilla, M. L., \& Tadeo, J. L. (2010). Mycotoxins in Fruits and Their Processed Products: Analysis, Occurrence and Health Implications. Journal of Advanced Research, 1, 113-122. https://doi.org/10.1016/j.jare.2010.03.002

Hans, P. V. E., \& Marco, A. J. (2005). Summary of Study, Carried out for the Food and Agriculture Organization. Worldwide regulations for mycotoxins in food and feed in 2003, (Food and Nutrition Paper No. 81). FAO.

Héctor, P.-C., Marta, H. T., Jorge, M. H., \& Hilary, C. d. M. (2003). Growth of Aspergillus Ochraceus, A. Carbonarius and A. Niger on Culture Media at Different Water Activities and Temperatures. Brazilian Journal of Microbiology, 36(1), 24-28.

Hertveldt, K., Saeger, S. D., Haesaert, G., \& Boevre, M. D. (2016). Mycotoxins Occurrence in Nigerian Cereal Crops (Sorghum and Millet). (Master), Ghent University.

Hope, J. H., \& Hope, B. E. (2011). A Review of the Diagnosis and Treatment of Ochratoxin A Inhalational Exposure Associated with Human Illness and Kidney Disease Including Focal Segmental Glomerulosclerosis. Journal of Environmental and Public Health, 2012, 1-11.

Limay-Rios, V., Miller, J. D., \& Schaafsma, A. W. (2017). Occurrence of Penicillium verrucosum, ochratoxin A, ochratoxin B and citrinin in on-farm stored winter wheat from the Canadian Great Lakes Region. PLoS ONE, 12(7), 1-22, https://doi.org/10.1371/journal.pone.0181239

Kenya national Bureau of Statistics, (2017). Population Distribution by Sex, Number of Households, Area and Density by County and District. Retrieved from https://www.knbs.or.ke/publications/

Milani, J. M. (2013). Ecological Conditions Affecting Mycotoxin Production in Cereals: A Review. Veterinarni Medicina, 58(8), 405-411. https://doi.org/10.17221/6979-VETMED

Milicevic, D., Nesic, K., \& Jaksic, S. (2015). Mycotoxin Contamination of the Food Supply Chain - Implications for One Health Programme. Procedia Food Science, 5, 187-190. https://doi.org/10.1016/j.profoo.2015.09.053

Misihairabgwi, J. M., Ezekiel, C. N., Sulyok, M., Shephard, G. S., \& Krska, R. (2017). Mycotoxin Contamination of Foods in Southern Africa: A 10-Year Review (2007-2016). Critical Reviews in Food Science and Nutrition, 1-16. https://doi.org/10.1080/10408398.2017.1357003

Nugroho, A. (2014). The Impact of Food Safety Standard on Indonesia's Coffee Exports. Procedia Environmental Sciences, 20, 425-433. https://doi.org/10.1016/j.proenv.2014.03.054

Oueslati, S., Blesa, J., Molto, J. C., Ghorbel, A., \& Manes, J. (2014). Presence of Mycotoxins in Sorghum and Intake Estimation in Tunisia. Food Addit Contam Part A Chem Anal Control Expo Risk Assess, 31(2), 307-318. https://doi.org/10.1080/19440049.2013.867367

Pitt, J. I. (2000). Toxigenic Fungi and Mycotoxins. British medical bulletin, 56, 184-192. https://doi.org/10.1258/0007142001902888

Reddy, L., \& Bhoola, K. (2010). Ochratoxins-Food Contaminants: Impact on Human Health. Toxins, 2, $771-779$. https://doi.org/10.3390/toxins2040771 
Sasmal, D., \& Mazumder, P. M. (2001). Mycotoxins - Limits and Regulations. Ancient Science of Life, 20, 1-18.

Sorrenti, V., Di Giacomo, C., Acquaviva, R., Barbagallo, I., Bognanno, M., \& Galvano, F. (2013). Toxicity of Ochratoxin A and Its Modulation by Antioxidants: A Review. Toxins, 5(10), 1742-1766. https://doi.org/10.3390/toxins5101742

Volkova, T. (2013). Mycotoxins in Brewing Grain Raw Material (Barley, Malt) in Russia. Journal of Food Science and Engineering, 3, 496-502.

Zinedine, A. (2010). Ochratoxin A in Moroccan Foods: Occurrence and Legislation. Toxins, 2, 1121-1133. https://doi.org/10.3390/toxins2051121.

\section{Copyrights}

Copyright for this article is retained by the author(s), with first publication rights granted to the journal.

This is an open-access article distributed under the terms and conditions of the Creative Commons Attribution license (http://creativecommons.org/licenses/by/4.0/). 